\title{
Development of a LC-IT-TOF MS Procedure to Quantify Veterinary Drug Residues in Milk Employing a QuEChERS Approach
}

\author{
Sueny Kêlia Barbosa Freitas • Ana Paula Silveira Paim • \\ Paula Tereza de Souza e Silva
}

Received: 2 November 2012 / Accepted: 13 February 2013

(C) Springer Science+Business Media New York 2013

\begin{abstract}
A sensitive liquid chromatography coupled to high-resolution tandem mass spectrometry (LC-IT-TOF MS) with electrospray ionization method for the identification and quantification of five antibiotic residues in milk has been developed. For sample preparation, a simple modification of the QuEChERS method was used with further sample cleanup using dispersive solid phase extraction according to AOAC official standards 2007.01. The method yielded acceptable accuracy values for each drug at each level, with mean recoveries $(n=3)$ ranging from 83 to $92 \%$. The recovery of antibiotics of the intra-assay ranged from 85 to $95 \%(\mathrm{RSD}<9 \%)$ and the inter-assay from 84 to $95 \%$ $(\mathrm{RSD}<11 \%)$. A total of 31 milk samples, either pasteurized or fresh whole milk, were analyzed following the method. Amoxicillin and oxytetracycline (two of the pasteurized milk samples), ampicillin and amoxicillin (3 of 25 fresh milk samples), and tetracycline and oxytetracycline (two other fresh milk samples out of 25) were detected at levels below the current Brazilian maximum residue levels.
\end{abstract}

Keywords Antibiotics $\cdot$ LC-IT-TOF MS · Milk · QuEChERS · Dispersive SPE (dSPE) · MRLs

\footnotetext{
S. K. B. Freitas · A. P. S. Paim $(\bowtie)$

Universidade Federal de Pernambuco, Centro de Ciências Exatas e da Natureza, Departamento de Química Fundamental, Av. Jornalista Aníbal Freire, s/n-Cidade Universitária, 50740-560 Recife, Pernambuco, Brazil

e-mail: anaspaim@ufpe.br

P. T. de Souza e Silva

Empresa Brasileira de Pesquisa Agropecuária, EMBRAPA

Semiárido, BR 428, Km 152, Zona Rural,

56302-970 Petrolina, Pernambuco, Brazil
}

\section{Introduction}

A wide variety of antibiotics, e.g., the classes of penicillins, tetracyclines, and amphenicol, are available for use as veterinary medicines. Penicillin residues in food, however, can cause allergic reactions in sensitive individuals (Kennedy et al. 1998). Tetracyclines, in addition to causing allergic reactions, may inhibit the development of children by interfering with calcium absorption, which will affect bone strength and teeth growth. The use of chloramphenicol in food products is banned in the USA, Canada, Europe, and Brazil due to its mutagenic and carcinogenic characteristics, even at low levels (O'Keeffe and Kennedy 1998).

In addition to safety issues, antibiotic residues in milk pose serious other concerns for various industries. These residues in milk may interfere in the fermentation process of cheese, yogurt, and butter, making it difficult to produce these products or by degrading their final quality (Almeida et al. 2003).

The European Union has established a regulation which has set maximum residue levels (MRLs) for veterinary drugs in different animal origin foods (Council Regulation No. 37/2010 and Official Journal of the European Communities L15/1 2010). The MRLs for chloramphenicol was established as zero.

Various multiclass methods have been reported to detect and quantify residues of veterinary drugs in milk. These include high-performance liquid chromatography with diode array detection (HPLC-DAD; Mamani et al. 2009; Gamba et al. 2009), liquid chromatography-tandem mass spectrometry (Rønning et al. 2006; Kinsella et al. 2009; Van Holthoon et al. 2010), capillary electrophoresis (CE) coupled to a UV/Vis detector (Santos et al. 2007), and ultra-performance liquid chromatography method combined with time-of-flight mass spectrometry (TOF-MS; Stolker et al. 2008). 
Due to the complexity of the matrix, some of methodologies such as HPLC-DAD and CE (Mamani et al. 2009; Gamba et al. 2009; Santos et al. 2007) are not able to detect for the required specificity and sensitivity. In recent years, the advancement of liquid chromatography coupled with mass spectrometry (LC-MS) has provided much better specificity and sensitivity to detect and quantify antibiotics in milk.

A quick, easy, cheap, effective, rugged, and safe (QuEChERS) method was developed (Anastassiades et al. 2003) as a simpler way to detect pesticide residues in fruit, vegetables, and other foods. The procedure is based on sample extraction with acetonitrile, followed by liquid-liquid partition and a novel dispersive solid phase extraction (dSPE) cleanup of the extract (Martín et al. 2010). Since its establishment, various changes were made to this approach so that it can be used for the analysis of different analyte samples (Lehotay et al. 2005, 2010; Plossl et al. 2006; Payá et al. 2007; Stubbings and Bigwood 2009). In 2007, the QuEChERS method was adopted as the official method of the Association of Official Analytical Chemists to determine pesticide residues in food (Capar et al. 2008).

Chromatographic techniques, principally high-performance LC-MS (Aguilera-Luiz et al. 2008), have been widely used for this purpose because of their sensitivity and selectivity, allowing the identification of several compounds at the same time (Sheridan et al. 2008).

Although various analytical methods have been reported to detect and quantify antibiotics in milk (Mamani et al. 2009; Gamba et al. 2009; Rønning et al. 2006; Kinsella et al. 2009; Van Holthoon et al. 2010; Santos et al. 2007; Stolker et al. 2008; Ortelli et al. 2009; Nebot et al. 2012), none of them have reported on the use of the QuEChERS method to extract milk for the detection and quantification of the particular antibiotics used in the present study.

In the present work, an analytical methodology was developed using liquid chromatography coupled to high-resolution tandem mass spectrometry (LC-IT-TOF MS) with electrospray ionization to identify and quantify antibiotic residues in industrially pasteurized milk samples sold for public consumption as well as in fresh milk taken from the dairies near the town of Garanhuns, in the State of Pernambuco. If the detection in milk samples were more precise, it would serve to alert the agencies involved in increasing their surveillance of antibiotic use in milk production.

\section{Experimental}

\section{Chemicals and Reagents}

Acetonitrile (HPLC grade) was from JT Baker (Phillipsburg, NJ). HPLC grade methanol (Sigma-Aldrich, St. Louis, MO) and HPLC water purified with a Milli-Q system (Millipore,
USA) were used. The antibiotics amoxicillin (AMOX, 99.9\%) and ampicillin (AMP, $99.9 \%$ ) were purchased from Sigma; tetracycline (TET, $99.0 \%$ ), oxytetracycline (OXY, $99.0 \%$ ), and chloramphenicol (CHLO, $99.0 \%$ ) were donated by the State of Pernambuco Pharmaceutical Laboratory (Laboratório Farmacêutico do Estado de Pernambuco-LAFEPE).

A $250-\mathrm{mgL}^{-1}$ stock solution of each antibiotic was prepared in methanol. This solution was stored in a freezer (from -18 to $-20{ }^{\circ} \mathrm{C}$ ) until use. The stock solutions were diluted with methanol and individual solutions containing $1,000 \mu \mathrm{gL}^{-1}$ AMOX, AMP, TET, and OXY and $100 \mu \mathrm{gL}^{-1}$ CHLO were prepared. The working solutions consisted of a mixture of all five antibiotics and the intermediate solutions were diluted in methanol. These working solutions were prepared daily. Stock solutions of TET, OXY, and CHLO were stable for a period of at least 40 days, AMOX for 30 days, and AMP for 7 days.

A Q-Sep 110 kit containing $4 \mathrm{~g} \mathrm{MgSO}_{4}, 1 \mathrm{~g} \mathrm{NaCl}, 1 \mathrm{~g}$ trisodium citrate dehydrate, and $0.5 \mathrm{~g}$ disodium hydrogen citrate sesquihydrate in a $50-\mathrm{mL}$ centrifuge tube was used for the extraction; the Q-Sep 250 kit with Bondesil primary secondary amine (PSA) and $\mathrm{MgSO}_{4}$ was used for the cleanup. The kits were purchased from Restek (Bellefonte, PA). All solutions used in HPLC were passed through $0.45-\mu \mathrm{m}$ membrane filters (Millipore, USA) before use. Millex ${ }^{\mathrm{TM}}$ syringe filter (pore size, $0.45 \mu \mathrm{m}$ ) was purchased from Millipore (Brazil).

\section{Apparatus Interface}

The system consisted of a liquid chromatography coupled with a hybrid mass spectrometer consisting of ion trapping and time of flight (LC-IT-TOF MS) from Shimadzu Corp. (Kyoto, Japan) equipped with a binary pump (model LC20AD, Shimadzu Corp.) and an autosampler (model SIL 20AC, Shimadzu Corp.). Chromatographic separation for antibiotics was performed with a Gemini C18 column $(50 \times 2.1 \mathrm{~mm}, 3 \mu \mathrm{m})$ from Phenomenex.

\section{LC/MS Analysis}

The interface between the LC and MS consisted of an electrospray ionization source with a negative mode $(-2.5 \mathrm{kV})$ and positive mode $(4.5 \mathrm{kV})$, a nebulizer gas flow $\left(\mathrm{N}_{2}\right)$ of $1.5 \mathrm{Lmin}^{-1}$, a drying gas $\left(\mathrm{N}_{2}\right)$ pressure of $100 \mathrm{kPa}$, and an interface temperature of $200{ }^{\circ} \mathrm{C}$. The quantification was based on the accurate $\mathrm{m} / \mathrm{z}$ of the precursor ion. The accumulation time of the ions in octopole was $30 \mathrm{~ms}$ and the mass spectra were acquired in both positive and negative ionization modes in the range of $m / z 300-500$.

The computer program Labsolutions LCMS Real Time Analysis (version 3.41, Shimadzu Corporation) was used for 
data acquisition. The Accurate Mass Calculator program (version 1.12, Shimadzu Corporation) was used to calculate the mass of antibiotics. A binary gradient mobile phase was used with phase $A$ (ultrapure water) and phase $B$ (methanol) working for $0-6 \min (\mathrm{A} / \mathrm{B}=70: 30, v / v), 6-20 \mathrm{~min}(\mathrm{~A} / \mathrm{B}=$ $50: 50, v / v), 20-25 \min (\mathrm{A} / \mathrm{B}=30: 70, v / v)$, and $25-35 \mathrm{~min}$ $(\mathrm{A} / \mathrm{B}=70: 30, v / v)$. This composition was maintained for 10 min before starting a new analysis.

The flow rate was $0.2 \mathrm{mLmin}^{-1}$ and the column temperature was set at $40{ }^{\circ} \mathrm{C}$. The injection volume sample was $5.0 \mu \mathrm{L}$; all five compounds were eluted within $35 \mathrm{~min}$ and the mass spectrum of each antibiotic in the samples was obtained. Prior to adopting the above final gradient conditions for the simultaneous determination of the five antibiotics, a number of different mobile phases such as acetonitrile and acidified water (with 0.1 or $0.2 \%$ formic acid) were evaluated. In addition, different column temperatures $\left(55,40\right.$, and $\left.35^{\circ} \mathrm{C}\right)$ and different flow rates $\left(0.1,0.2\right.$, and $\left.0.5 \mathrm{mLmin}^{-1}\right)$ were evaluated to optimize their separation.

\section{Sample Preparation and Extraction}

Raw milk samples were collected from different dairies near the city of Garanhuns in the state of Pernambuco (Brazil). Commercial pasteurized milk samples were purchased in different supermarkets in the city of Recife in the state of Pernambuco. To evaluate the method, milk completely free of antibiotic residues, collected from Quixaba dairy, located in Santa Teresa, state of Paraiba (Brazil), was used.

Samples were collected into 50-mL Falcon tubes (plastic container), frozen, and transported to the laboratory Styrofoam boxes containing ice cube bags. The tubes containing the samples were stored in a freezer at -18 to $-20{ }^{\circ} \mathrm{C}$ until use. The sample preparation procedure was developed using the QuEChERS methodology (Prestes et al. 2009), with minor adjustments as described below. An aliquot of $10 \mathrm{~mL}$ of milk sample was placed in a Falcon tube, fortified with antibiotics, and left to stand for $15 \mathrm{~min}$. A Q-Sep $110 \mathrm{kit}$ and a Q-Sep 250 kit were used for the extraction and cleanup of samples, respectively.

The extraction was performed by adding $10 \mathrm{~mL}$ acetonitrile to the Q-Sep 110 kit followed by the addition of the spiked sample. The sample was immediately swirled for $1 \mathrm{~min}$ and centrifuged (Sigma laboratory centrifuge model 6-15, Osterode, Germany) at 3,700 $\mathrm{rpm}(4,120 \times \mathrm{g})$ for $5 \mathrm{~min}$. The cleanup was carried out by transferring $1.0 \mathrm{~mL}$ of the supernatant to the Q-Sep 250 kit. The sample extract was swirled for $1 \mathrm{~min}$ and centrifuged (Eppendorf centrifuge model 5430, Hamburg, Germany) at 3,000 rpm $(5,165 \times \mathrm{g})$ for $2 \mathrm{~min}$. An aliquot of the resulting supernatant was passed through a $0.45-\mu \mathrm{m}$ Maxcrom OE syringe filter. The collected filtrate was transferred to a vial for further analysis by LC-MS.

\section{Validation Method}

Linearity, selectivity, repeatability, recovery, inter-day and intra-day precision, and the limits of detection (LOD) and quantification (LOQ) were calculated to validate the whole procedure following the guidelines set by ANVISA (ANVISA, Resolution RDC 27 from May 17, 2012).

Linearity was evaluated using matrix-matched calibration, spiking blank extracts at seven concentration levels of 2.0, 4.0, 6.0, 8.0, 9.0, 10.0, and $12.0 \mu \mathrm{gL}^{-1}$ for amoxicillin and ampicillin; 20.0, 50.0, 75.0, 100.0, 200.0, 300.0, and $400.0 \mu \mathrm{gL}^{-1}$ for oxytetracycline and tetracycline; and $0.3,0.5,0.7,0.9,1.1$, and $1.3 \mu \mathrm{gL}^{-1}$ for chloramphenicol. To evaluate the linearity, the mean value of three signals $(n=3)$ at the same concentration was used. The concentration limits for the analytical curve were defined from the MRL values of each antibiotic: $4.0 \mu \mathrm{gL}^{-1}$ for AMOX and AMP; $100 \mu \mathrm{gL}^{-1}$ for TET and OXY; and $0.3 \mu \mathrm{gL}^{-1}$ for CHLO.

The accuracy of the method was evaluated following the QuEChERS approach: $10 \mathrm{~mL}$ of a control milk sample was poured into Falcon tubes and appropriate volumes of working stock solutions of antibiotics were added to the samples at three concentration levels: 2.0, 8.0, and $12 \mu \mathrm{gL}^{-1}$ of AMOX and AMP; 20, 100, and $400 \mu \mathrm{gL}^{-1}$ of TET and OXY; and $0.3,0.9$, and $1.3 \mu \mathrm{gL}^{-1}$ of CHLO. The samples were subjected to the extraction procedure described in "Sample Preparation and Extraction."

Repeatability (intra-day precision) and reproducibility (inter-day precision) were evaluated at the above three concentration levels. To evaluate intra-day precision, the entire procedure was carried out on the same day by a single operator. Inter-day precision was evaluated by repeating the same procedure on three consecutive days.

The LODs and LOQs of each analytes were determined as the lowest amounts of each analyte for which the signalto-noise ratios $(\mathrm{S} / \mathrm{N})$ were 3 and 10 , respectively. LODs and LOQs were estimated by fortifying blank samples with antibiotics at LOQ levels (AMP and AMOX, $2.0 \mu \mathrm{gL}^{-1}$; TET and OXY, $20 \mu \mathrm{gL}^{-1}$; and CHLO, $0.3 \mu \mathrm{gL}^{-1}$ ) and measuring the same samples 20 times to calculate the standard deviation of measurement. Finally, the selectivity of the method was evaluated by analyzing ten control blank samples from Quixaba dairy.

\section{Results and Discussion}

Optimization of the Chromatographic Conditions

The initial chromatographic conditions were established based on those described in the literature (Rønning et al. 2006; Ortelli et al. 2009; Van Holthoon et al. 2010). 
Fig. 1 Mass spectra obtained for ampicillin $(A M P)$ and oxytetracycline $(O X Y), \mathrm{m} / \mathrm{z}$ 348.0989 and 443.1443, respectively, in a positive ionization mode. Tetracycline (TET) and chloramphenicol (CHLO), $\mathrm{m} / \mathrm{z} 459.1372$ and 323.0002 , respectively, in a negative mode. Amoxicillin (AMOX) $\mathrm{m} / z 396.1202$ that formed an adduct with methanol. All solutions were $100 \mu \mathrm{g} \mathrm{L}^{-1}$ of antibiotic

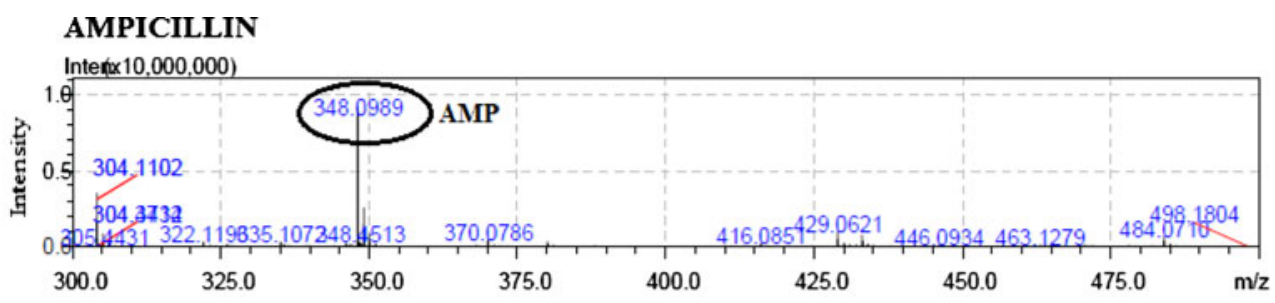

OXYTETRACYCLINE

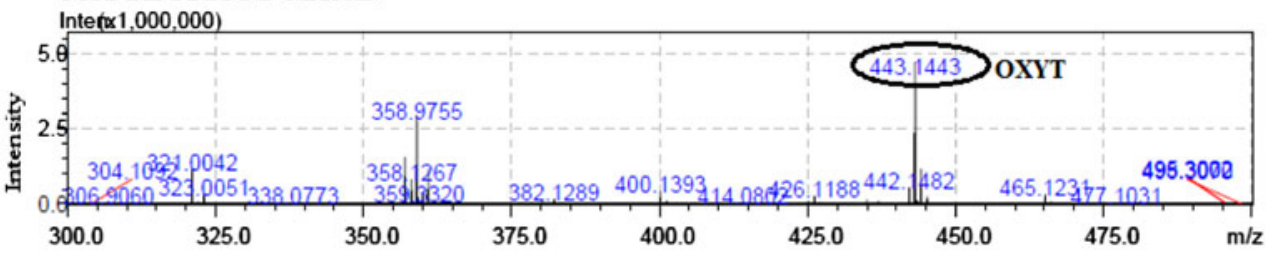

TETRACYCLINE

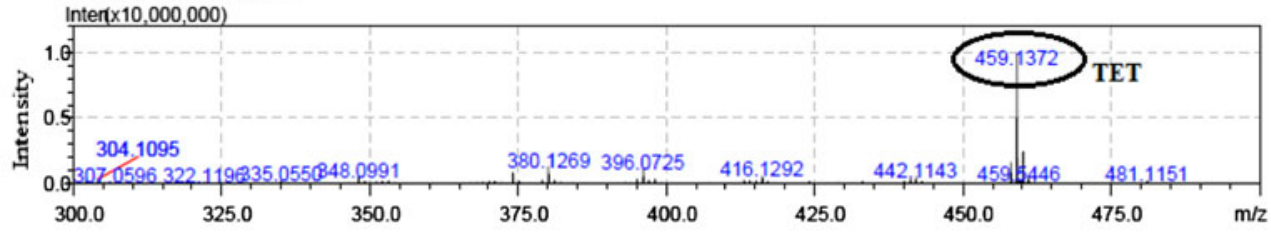

CHLORAMPHENICOL
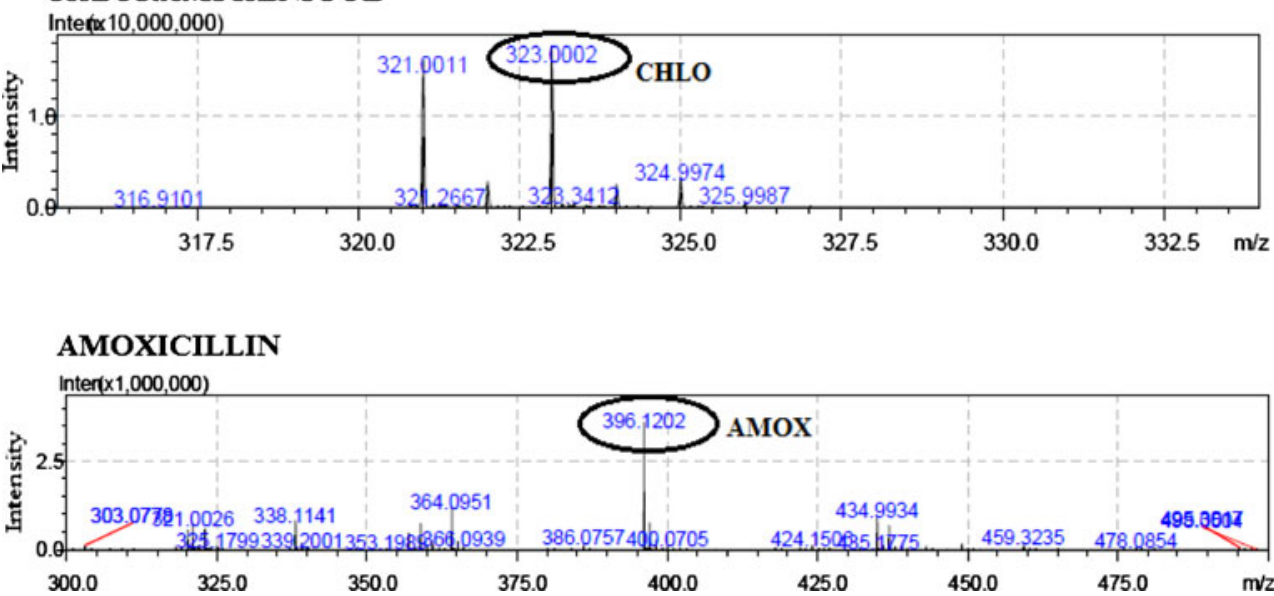

However, it was necessary to make some adjustments in order to optimize the separation of the five antibiotics.

Different mobile phases consisting of acetonitrile or methanol as the organic phase and acidified water with different concentrations of formic acid $(0.1-0.2 \%)$ as the aqueous phase were tested to achieve an optimal chromatographic separation and high MS signal response for the drugs selected. When acetonitrile was used as an organic phase and acidified water with formic acid in different concentrations $(0.1-0.2 \%)$ as the aqueous phase, the analysis of the solutions showed no separation of the tetracycline. Tetracyclines are substances that show up a great amount of substituent hydroxyl $(-\mathrm{OH})$ in this structure. Hydroxyl exhibits moderate affinity for organic solvents such as acetonitrile. Moreover, when acidified water with formic acid was used, there was a significant increase in the ionization compounds, making detection difficult. The best separation with the best ionization was obtained when methanol (organic phase) and water (without acidification) were used. The neutral $\mathrm{pH}$ of the mobile phase assisted in the separation of the five analytes.

The influence of the column temperature in the separation of antibiotics was evaluated. The temperatures tested were 55, 40, and $35^{\circ} \mathrm{C}$; the best separation between signals was observed at $40{ }^{\circ} \mathrm{C}$. To improve the efficiency separation, three flows of the mobile phase were tested: $0.1,0.2$, and $0.5 \mathrm{mLmin}^{-1}$; flow at $0.2 \mathrm{mLmin}^{-1}$ was selected. Thus, the effluent generated and solvent volumes consumed were diminished comparing with flow conditions at $0.5 \mathrm{mLmin}^{-1}$. 


\section{a) $\mathrm{CHLO}$}

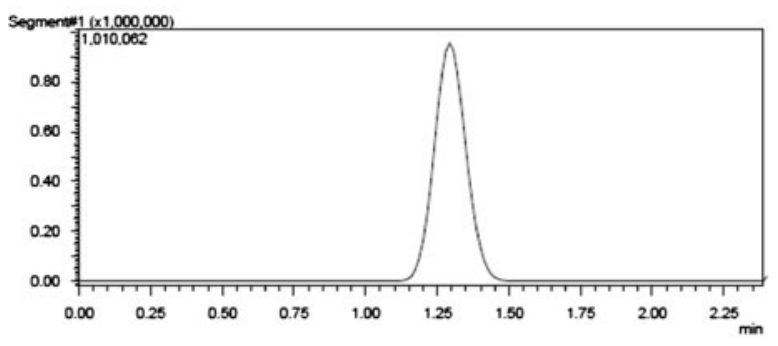

\section{c)AMP}

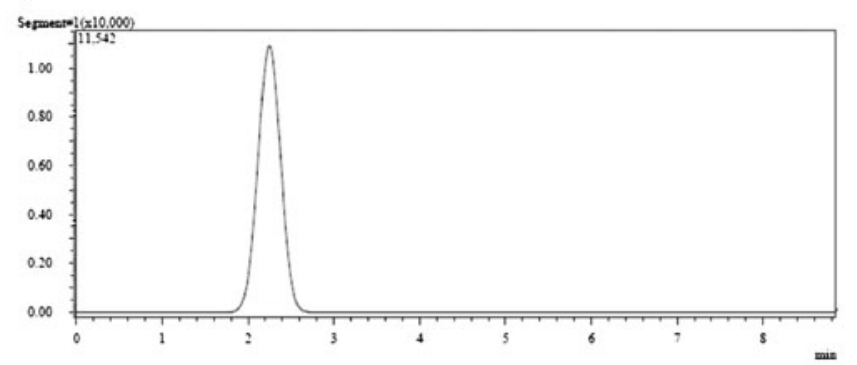

b)AMOX

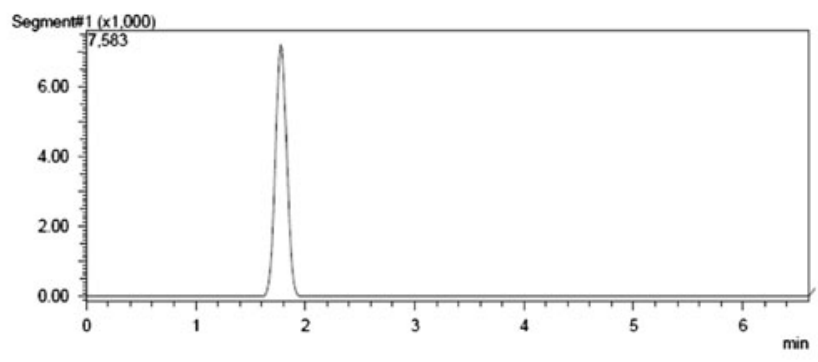

d) TETR

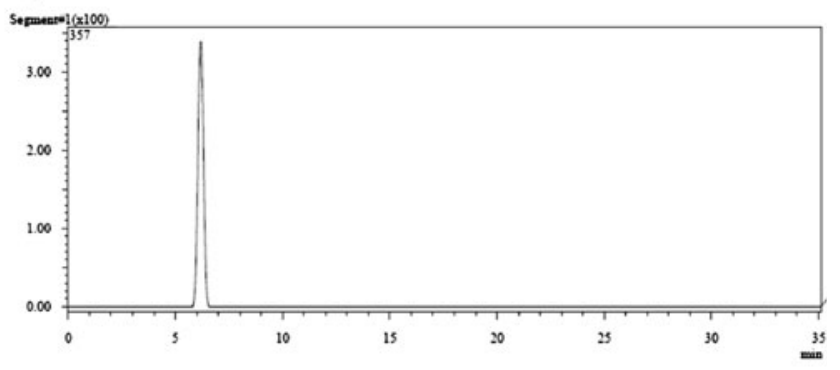

\section{e) OXY}

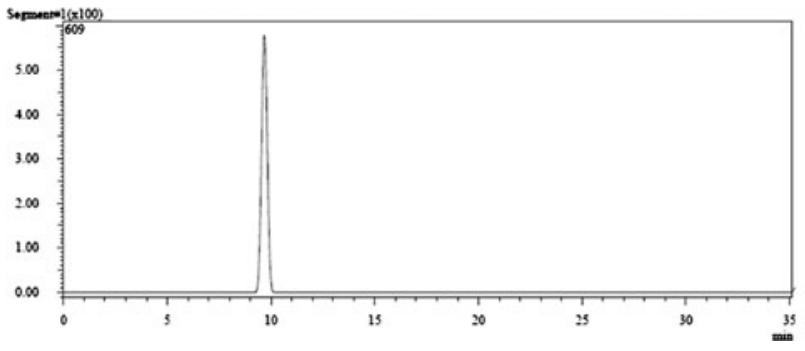

Fig. 2 LC-IT-TOF MS chromatograms of a blank milk fortified with antibiotics. a Chloramphenicol $\left(C H L O, 100 \mu \mathrm{g} \mathrm{L} \mathrm{L}^{-1}\right)$. b Amoxicillin $(A M O X$, $\left.1,000 \mu \mathrm{g} \mathrm{L}{ }^{-1}\right)$. c Ampicillin $\left(A M P, 1,000 \mu \mathrm{g} \mathrm{L}^{-1}\right)$. d Tetracycline $\left(T E T, 1,000 \mu \mathrm{g} \mathrm{L}^{-1}\right)$. e Oxytetracycline $\left(O X Y, 1,000 \mu \mathrm{g} \mathrm{L}^{-1}\right)$

\section{LC-IT-TOF MS Analysis}

The identification of each individual antibiotic was performed by injecting $100 \mu \mathrm{gL}^{-1}$ of each analyte into the mass spectrometer with an infusion pump. The mass spectral parameters were optimized as follows: electrospray ionization source energy capillary of $4.5 \mathrm{kV}$ (positive mode) and $-2.5 \mathrm{kV}$ (negative mode) with a source temperature at $200{ }^{\circ} \mathrm{C}$.

The most abundant fragment ions were selected based on the mass spectra of each analyte (Fig. 1). AMP and OXY formed the protonated ion $[\mathrm{M}+\mathrm{H}]^{+}$ ( $\mathrm{m} / \mathrm{z} 348.09$ and 443.14 , respectively) in a positive ionization mode, while TET and CHLO formed deprotonated ions $[\mathrm{M}-\mathrm{H}]^{-}(\mathrm{m} / \mathrm{z} 459.14$ and 323.00 , respectively) in a negative ionization mode. Finally AMOX formed an adduct ion with methanol $\left[\mathrm{M}+\mathrm{CH}_{3} \mathrm{OH}-\mathrm{H}\right](\mathrm{m} / z 396.12)$ as the most abundant ion. These ions were selected as the precursor ions for quantification.
Using the conditions described in the experimental section, all veterinary drugs were well separated and eluted from $1.2 \mathrm{~min}$ (CLO) to $10 \mathrm{~min}$ (OXY) (Fig. 2).

Sample Preparation Procedure

As mentioned above, an approach modified from the QuEChERS method was used for the extraction of the five analytes in milk.

Acetonitrile was used as an extraction solvent because of its miscibility with water, which provides a single phase extract containing smaller amounts of lipophilic coextractives from the sample, e.g., waxes, fats, and pigments (Mastovska and Lehotay 2004).

The addition of salts in the extraction process enhanced the extraction recovery by yielding better separation of the organic and aqueous phases. The QuEChERS method employs a mixture of $1 \mathrm{~g}$ of sodium chloride $(\mathrm{NaCl})$ and $4 \mathrm{~g}$ of magnesium sulfate $\left(\mathrm{MgSO}_{4}\right)$, which serves to remove water. 
Table 1 Linear range of concentration, analytical curve equation, and determination coefficient for each analyte under study

\begin{tabular}{llll}
\hline Analyte & $\begin{array}{l}\text { Concentration } \\
\text { range }\left(\mu \mathrm{gL}^{-1}\right)\end{array}$ & $\begin{array}{l}\text { Equation of } \\
\text { analytical curve }\end{array}$ & $R^{2}$ \\
\hline AMP & $2.0-12.0$ & $S=15,298 C-7,951.2$ & 0.9962 \\
AMOX & $2.0-12.0$ & $S=14,413 C-3,954.6$ & 0.9989 \\
TET & $20.0-400$ & $S=11,670 C+2 \times 10^{6}$ & 0.9996 \\
OXY & $20.0-400$ & $S=11,829 C+2 \times 10^{6}$ & 0.9979 \\
CHLO & $0.3-1.3$ & $S=468,308 C-96,406$ & 0.9985 \\
\hline
\end{tabular}

$S$ signal, $C$ concentration

Its adsorption of moisture is exothermic, resulting in the heating of sample between 40 and $45{ }^{\circ} \mathrm{C}$ during the extraction and partitioning steps, which reduces the volume of the aqueous phase (Martín et al. 2010). The sample cleanup using $\mathrm{NaCl}$ minimized the need for cleaning of the mass spectrometry ionization source (Stolker et al. 2008).

The next step in the sample preparation included the cleanup using $25 \mathrm{mg}$ PSA and $150 \mathrm{mg} \mathrm{MgSO}_{4}$. This final cleanup step enabled the removal of most of the co-extracted matrices.

\section{Method Validation}

\section{Matrix-Matched Calibration Curves}

Linear calibration curves were obtained for each of the five antibiotics using mixed standard solutions. The equation of each analytical curve was based on the mean signal of three replicate injections of each standard. Correlation coefficients higher than 0.99 were observed with calibration curves in the concentration ranges evaluated for all five analytes (Table 1).
Table 3 Comparison among MRLs established by legislation (ANVISA 2009; MAPA 2010; EC 2010) and the LOD and LOQ obtained using the proposed method to determine antibiotics in milk employing LC-IT-TOF MS

\begin{tabular}{llll}
\hline Antibiotics & MRL $\left(\mu \mathrm{gL}^{-1}\right)$ & $\mathrm{LOD}\left(\mu \mathrm{gL}^{-1}\right)$ & $\mathrm{LOQ}\left(\mu \mathrm{gL}^{-1}\right)$ \\
\hline AMP & 4.0 & 0.28 & 0.94 \\
AMOX & 4.0 & 0.13 & 0.43 \\
OXY & 100 & 1.92 & 6.39 \\
TET & 100 & 1.42 & 4.72 \\
CHLO & 0.0 & 0.0075 & 0.025 \\
\hline
\end{tabular}

\section{Selectivity}

The method selectivity tests $(n=10)$ showed that interferences resulted from isomers, metabolites, degradation products, and matrices were not detectable or all were below the allowed limit, partly due to the high selectivity of MS.

\section{Recovery (Accuracy) and Precision}

The recoveries of each antibiotic spiked at different levels and the inter- and intra-assay precision in milk are shown in Table 2. The antibiotics were fortified at levels of 2.0, 8.0, and $12.0 \mu \mathrm{gL}^{-1}$ (AMOX and AMP); 20.0, 100.0, and $400.00 \mu \mathrm{gL}^{-1}$ (OXY and TET); and 0.3, 0.9, and $1.3 \mu \mathrm{gL}^{-1}$ (CHLO) on three different days and also on the same day. Percent recovery was determined by comparing the peak area of the antibiotics extracted from the spiked samples (QC) with those of the calibration standard samples obtained under the same LC-IT-TOF MS. The recovery data ranged from $83 \%$
Table 2 Recovery, repeatability, and reproducibility of the LC-IT-TOF MS method for the determination of antibiotics fortified in milk samples

\begin{tabular}{|c|c|c|c|c|c|c|}
\hline \multirow{16}{*}{$\begin{array}{l}\text { LC-IT-TOF MS method for the } \\
\text { determination of antibiotics } \\
\text { fortified in milk samples }\end{array}$} & Analyte & $\begin{array}{l}\text { Spiked } \\
\text { level }\left(\mu g \mathrm{~L}^{-1}\right)\end{array}$ & Recovery (\%) & RSD (\%) & $\begin{array}{l}\text { Repeatability } \\
\text { (intra-assay) RSD (\%) }\end{array}$ & $\begin{array}{l}\text { Reproducibility } \\
\text { (inter-assay) RSD (\%) }\end{array}$ \\
\hline & AMP & 2.0 & 90 & 3.5 & 4.3 & 6.4 \\
\hline & & 8.0 & 83 & 8.8 & 3.5 & 6.6 \\
\hline & & 12.0 & 86 & 1.9 & 3.2 & 9.7 \\
\hline & AMOX & 2.0 & 88 & 2.5 & 6.4 & 5.6 \\
\hline & & 8.0 & 91 & 3.8 & 4.8 & 8.0 \\
\hline & & 12.0 & 88 & 4.4 & 6.9 & 9.1 \\
\hline & OXY & 20.0 & 92 & 2.4 & 8.1 & 8.9 \\
\hline & & 100.0 & 90 & 2.1 & 4.2 & 5.4 \\
\hline & & 400.0 & 87 & 1.1 & 5.2 & 6.2 \\
\hline & TET & 20.0 & 92 & 3.2 & 8.8 & 6.5 \\
\hline & & 100.0 & 91 & 4.5 & 5.0 & 10.3 \\
\hline & & 400.0 & 91 & 1.1 & 3.8 & 6.3 \\
\hline & CHLO & 0.3 & 92 & 3.2 & 3.1 & 8.6 \\
\hline & & 0.9 & 85 & 2.4 & 3.0 & 5.1 \\
\hline & & 1.3 & 89 & 2.4 & 3.6 & 6.7 \\
\hline
\end{tabular}

$n=3$ 
for AMP (RSDs $<8.8)$ to $92 \%$ for OXY $($ RSDs $<2.4)$, TET (RSDs $<4.5$ ), and CHLO (RSDs $<3.2$ ), demonstrating the accuracy of the QuEChERS method. The recovery of antibiotics of the intra-assay, which is fortified within the same day, ranged from 85 to $95 \%$ with a RSD of $<9 \%$. The recoveries of the antibiotics of the inter-assay fortified on different days range from 84 to $95 \%$ with a RSD of $<11 \%$. These recoveries and RSDs indicated the accuracy and precision of the method and the possibility of it being used for quantifying antibiotics in milk samples.

\section{$L O D$ and $L O Q$}

The method LOD and LOQ, calculated as three and ten times the signal-to-noise ratio, are presented in Table 3. The values obtained are of the same order or better than those reported in the literature using other extraction techniques (Junza et al. 2011; Gamba et al. 2009) and are lower than the MRL established by Brazilian legislation (MAPA 2010), except for chloramphenicol, the MRL of which was set at 0 .

\section{Milk Sample Analyses}

Ten pasteurized milk samples and 25 fresh milk samples were subjected to the method under discussion to detect and quantify the residue levels of five antibiotics. The detected residue levels of each antibiotic were in compliance with the MRL standards established by Brazilian legislation and different EU legislations (EC 2010) in most of the tested milk samples. Among them, two of the pasteurized milk samples were positive for amoxicillin and oxytetracycline and five of the fresh milk samples were positive for AMP, OXY, TET, and AMOX at a level above the MRL standards established by legislation (O'Keeffe and Kennedy 1998; Mamani et al. 2009; MAPA 2010).

The presence of antibiotics in milk indicates the incorrect use of drugs in livestock. The use of antibiotics is not allowed for lactating cows, and the detection of antibiotics in milk samples is indicative of poor veterinary practice. This proves that more strict guidance should be implemented in milk production in order to provide milk without antibiotic residues for public consumption.

\section{Conclusion}

A sensitive method for the determination of AMOX, AMP, CHLO, OXY, and TET in milk with LC-IT-TOF MS was developed. This method presented satisfactory results with respect to sensitivity, selectivity, accuracy, and precision. Consequently, the method can be used to quantify these veterinary drug residues in milk as routine analysis.
Acknowledgments Financial supports from CAPES, CNPq, and FACEPE are gratefully acknowledgement. The authors are grateful to Professor Suzana P.V. Nova (UAG-UFRPE) and Professor Lilian S.S. de Andrade (UFRPE) for help in collecting and sending milk samples and for suggestions ans to Severino Granjeiro Junior (LAFEPE), Rogério Ferreira da Silva (UFPE), and Edén Cavalcanti de Albuquerque Júnior (ITEP) for technical support.

Conflict of Interest Sueny Kêlia Barbosa Freitas declares that she has no conflict of interest. Ana Paula Silveira Paim declares that she has no conflict of interest. Paula Tereza de Souza e Silva declares that she has no conflict of interest. This article does not contain any studies with human or animal subjects.

\section{References}

Aguilera-Luiz MM, Vidal JLM, Romero-González R, Frenich AG (2008) J Chromatogr A 1205:10-16

Almeida LP, Vieira RL, Rossi DA, Carneiro AL, Rocha ML (2003) Biosci J 19:83-87

Anastassiades M, Lehotay SJ, Stajnbaher D, Schenck FJ (2003) J AOAC Int 86:412-431

ANVISA (2009) Agência Nacional de Vigilância Sanitária. Programa de Análise de Resíduos de Medicamentos Veterinários em Alimentos de Origem Animal-PAMVET- Relatório 2006-2007, Monitoramento de Resíduos em Leite Expostoao Consumo $\left(5^{\circ} \mathrm{e}\right.$ $6^{\circ}$ ano de atividades) Brasília (DF): http://portal.anvisa.gov.br/ wps/wcm/connect/d7ab358047458ad19443d43fbc4c6735/ PAMVET.pdf?MOD=AJPERES. Accessed 6 Mar 2013

Capar SG, Cook JM, Bell J, Hickes H, Krynitsky AJ, Lehotay SJ, Ritland CL, Schenck FJ, Soderberg D, Phillips J (2008) J AOAC Int 91:46B-48B

EC (2010) Council Regulation (EC) 37/2010/EC of 22 December 2009 on pharmacologically active substances and their classification regarding maximum residue limits in foodstuffs of animal origin (2010). Off J Eur Comm L15:1-72

Gamba V, Terzano C, Fiorini L, Moretti S, Dusi G, Galarini R (2009) Anal Chim Acta 637:18-23

Junza A, Amatya R, Barrón D, Barbosa J (2011) J Chromatogr B 879:2601-2610

Kennedy DG, Mccracken RJ, Cannavan A, Hewitt SA (1998) J Chromatogr A 812:77-98

Kinsella B, Lehotay SJ, Mastovska K, Lightfield AR, Furey A, Danaher M (2009) Anal Chim Acta 637:196-207

Lehotay SJ, De Kok A, Hienistra M, van Bodegraven P (2005) J AOAC Int 88:595-614

Lehotay SJ, Son KA, Kwon H, Koesukwiwat U, Fu W, Mastovska K, Hoh E (2010) J Chromatogr A 1217:2548-2560

Mamani MCV, Reyes FGR, Rath S (2009) Food Chem 117:545552

MAPA (2010) Ministério de Agricultura, Pecuária e Abastecimento do Brasil-MAPA - Programa Nacional de Controle de Resíduos e Contaminantes em Leite-PNCRC-Diário oficial da uniãoseção 1 ISSN 1677-7042, 03 de Maio de 2010

Martín SH, Pinto CG, Pavón JLP, Cordero BM (2010) J Chromatogr A 1217:4883-4889

Mastovska K, Lehotay SJ (2004) J Chromatogr A 1040:259-272

Nebot C, Iglesias A, Regal P, Miranda J, Cepeda A, Gente C (2012) Int Dairy J 22:78-85

O'Keeffe M, Kennedy O (1998) J Food Saf 18:297-319

Ortelli D, Cognard E, Jan P, Edder P (2009) J Chromatogr B $877: 2363-2374$ 
Payá P, Anastassiades M, Mack D, Sigalova I, Tasdelen B, Oliva J, Barba A (2007) Anal Bioanal Chem 389:1697-1714

Plossl F, Giero M, Bracher F (2006) J Chromatogr A 1135:19-26

Prestes OD, Friggi CA, Adaime MB, Zanella R (2009) Quím Nova 32:1620-1634

Rønning HT, Einarsen K, Asp TN (2006) J Chromatogr A 1118:226-233

Santos SM, Henriques M, Duarte AC, Esteves VI (2007) Talanta 71:731-737
Sheridan R, Policastro B, Thomas S, Rice D (2008) J Agric Food Chem 56:3509-3516

Stolker AAM, Rutgers P, Oosterink E, Lasaroms JJP, Peters RJB, van Rhijn JA, Nielen NWF (2008) Anal Bioanal Chem 391:23092322

Stubbings G, Bigwood T (2009) Anal Chim Acta 637:68-78

van Holthoon F, Mulder PPJ, van Bennekom EO, Heskamp H, Zuidema T, van Rhijn HJA (2010) Anal Bioanal Chem 396:3027-3040 